\title{
Ventral hernia: retrospective cost analysis of primary repair, repair with synthetic mesh, and repair with acellular xenograft implant
}

This article was published in the following Dove Press journal:

Open Access Surgery

30 May 2013

Number of times this article has been viewed

\author{
George DeNoto III' \\ Nancy Reaven ${ }^{2}$ \\ Susan Funk ${ }^{2}$ \\ 'Division of General Surgery, \\ St Francis Hospital, Roslyn, and Hofstra \\ North Shore-LIJ School of Medicine, \\ Manhasset, NY, USA; ${ }^{2}$ Strategic Health \\ Resources, La Cañada, CA, USA
}

Background: The purpose of this study was to evaluate resource utilization and costs of repair of potentially contaminated/infected complex ventral hernias using primary repair, synthetic mesh, or acellular xenograft.

Methods: We used 2008-2009 insurance claims (Truven Health Analytics MarketScan ${ }^{\circledR}$ ) to identify patients who underwent grade 3 or 4 ventral hernia repair between January 1 and June 30, 2008. Patients were categorized into synthetic mesh or xenograft groups based on Current Procedural Terminology and Healthcare Common Procedure Coding System codes, with primary repair identified by the absence of mesh or xenograft codes. Claims were reviewed for an 18-month post-procedure period to identify the incidence of medical complications, number of post-index events, and hospital costs.

Results: A total of 740 patients were included. Complication rates in grade 3 patients were significantly lower with xenograft (18\%) and primary repair (24\%) versus synthetic mesh $(37 \%$, $P=0.001)$. There were minimal differences between grade 4 patients. In grade 3 patients, synthetic mesh was associated with hospital returns for complications about three times as often as those with xenograft repairs and significantly more often than those with primary repairs $(P<0.0001)$. The average treatment cost for a xenograft repair in grade 3 patients was $\$ 33,266$ versus a primary repair at $\$ 34,948$ and synthetic mesh at $\$ 35,891$ (difference not statistically significant). In grade 4 patients, there was no statistically significant difference between the study arms in the rate of returns for treatment of complications or costs.

Conclusion: In this analysis of grade 3 and 4 hernia repair, total 18-month costs were similar across the three study arms despite some significant differences in complications favoring xenograft and primary repair over synthetic mesh.

Keywords: synthetic mesh, acellular xenograft, ventral hernia, cost analysis

\section{Introduction}

Ventral hernias are a common complication of abdominal surgery, with a significant impact on health care utilization and costs. In 2006, approximately 350,000 ventral hernia repairs were performed in the US, with procedure-related costs estimated at $\$ 3.2$ billion (standardized to 2010 US dollars). ${ }^{1}$ These costs did not include complications associated with ventral hernia repair (eg, infection, recurrence), which add substantially to the cost of caring for these patients. Currently, a number of techniques are available for ventral hernia repair, and while the optimal method of repair has not been identified, primary repair with mesh reinforcement is among the most commonly used techniques. Despite a growing body of literature evaluating new techniques and outcomes, there is a lack of consensus regarding the optimal type of mesh for repair. ${ }^{2}$
Correspondence: George DeNoto III Division of General Surgery, St Francis Hospital and Hofstra North Shore-LIJ School of Medicine, I39 Plandome Road, Manhasset, NY I 1030, USA

$\mathrm{Tel}+\mathrm{I} 5166275262$

Fax + I $516627064 \mid$

Email george.denoto@chsli.org 
The Ventral Hernia Working Group (VHWG) developed a grading system to categorize patients based on risk of surgical site occurrences, with recommendations to guide surgeons regarding the optimal type of mesh to use. ${ }^{3}$ The system uses patient and wound characteristics to define four grades with progressively increasing risk. Grade 3 includes potentially contaminated patients with a previous wound infection, stoma, or other procedure involving violation of the gastrointestinal tract performed concurrent with the ventral hernia repair, and grade 4 includes patients with infected mesh or septic dehiscence. In grade 3 and 4 patients, the VHWG concludes that synthetic mesh is generally not recommended and biologic mesh should be considered.

In this study, we retrospectively evaluated the health care resource utilization and costs associated with repair of grade 3 and 4 ventral hernias using primary hernia repair alone, repair using synthetic mesh, and repair using a xenograft. Health care resources included length of stay and return hospital visits for recurrences and complications. Hospital costs were estimated for initial repairs and postoperative complications/reoperations.

\section{Materials and methods}

We used 2008-2009 insurance claims from US private and Medicare plans from Truven Health Analytics MarketScan ${ }^{\circledR}$ research databases to identify all patients who had an inpatient grade 3 or 4 ventral hernia repair between January 1 and June 30, 2008, which was designated as the "index event". Procedures were defined by Current Procedural Terminology $\left(\mathrm{CPT}^{\circledR}\right)$ codes 49560, 49561, 49565, or 49566 (repair initial or recurrent hernia, either incarcerated or strangulated), 49652-49657 (laparoscopy, repair, ventral/ incisional hernia, either incarcerated/strangulated) or 49659 (unlisted laparoscopic hernia repair). Patients were required to have a minimum of 12 months of continuous insurance coverage following the index event, except for death (as identified by inpatient discharge status).

Ventral hernias were grouped by grade using diagnosis and procedure codes to approximate the criteria specified by the VHWG (Table 1). ${ }^{3}$ For grade 3 (potentially contaminated), relevant codes occurring in services up to six months prior to the index date were used to identify previous wound infection (including previous septicemia or dehiscence); procedure codes at index date \pm 2 days identified concurrent violation of the gastrointestinal tract or stoma creation. For grade 4 (infected), infected mesh was identified if mesh was removed in conjunction with the hernia repair being graded, if debridement was performed or an abscess was drained 0-2 days prior to the index date, or if confirmed by a combination of diagnosis and procedure codes during the hospital stay. Due to limitations of the data, septic dehiscence was defined as the presence of code(s) confirming either septicemia or dehiscence at index \pm 2 days. To avoid confusion in attribution of complications, patients were excluded for bariatric surgery during the index event or post-transplant status at index. Codes defining each condition are listed in the online appendix.

Patients meeting the selection criteria were classified by study arm based on CPT or Healthcare Common Procedure Coding System (HCPCS) codes: synthetic mesh was defined by HCPCS C1781 or CPT 49568 (hernia repair with mesh add-on code) in a grade 3 hernia. Xenograft was defined by CPT 15430 or 15431 (acellular xenograft implant) or HCPCS $\mathrm{J} 7347$ (nonmetabolic active tissue, nonhuman). Further, any grade 4 hernia repair described as CPT 49568 was assigned to the xenograft arm. This is based on coding practices in 2008 before more specific HCPCS codes were introduced, and because clinical guidelines recommend against using synthetic mesh in an infected hernia. ${ }^{3}$ Index events involving none of the aforementioned codes were assumed to involve primary repair.

Each patient's insurance claims for an 18-month postindex (study) period were reviewed to identify services related to the hernia repair. Complications and hernia recurrences were identified by diagnosis code and/or CPT or ICD9-CM procedure code (see online appendix) and grouped into categories for reporting purposes. A complication was

Table I Ventral hernia working group hernia grading system

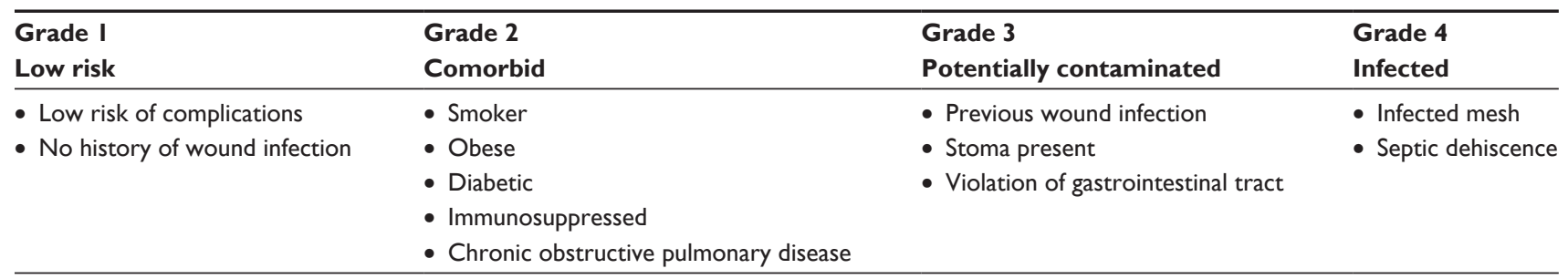

Note: Reprinted from Surgery, I48/3, Breuing K, et al. Incisional ventral hernias: Review of the literature and recommendations regarding the grading and technique of repair, 544-558, @2010, with permission from Elsevier. ${ }^{3}$ 
included if it occurred during a defined post-procedure validity period (Table 2 ) following the index event or a subsequent hernia repair, and excluded if analysis of claims for intervening services revealed a potential alternative cause for the complication.

The identification of infected mesh (removal) was sensitive to timing and study arm because some xenograft matrices are incorporated into the host tissue and are generally not removed after approximately 90 days, while synthetic mesh remains physically distinct and can be removed. Except for this limitation, the methodology assumes that mesh, if infected, was removed, and that mesh, if removed, was infected (detailed description in online appendix). Accordingly, infected mesh with removal was a subset of the infection category. Hospital visits/admissions subsequent to the index ventral hernia repair and involving a complication or a hernia recurrence were identified as post-index events; physician office visits were not included. Events involving multiple complication(s) were classified according to the highest priority complication present (see Table 2). In the analysis of patient complication rates, each complication identified in any post-index event was counted once per patient. In the analysis of event rates, each readmission or return visit for complication(s) and/or related hernia procedure(s) was counted once. Post-index event results were normalized as rates per 100 patients to facilitate comparison between study arms.

The presence of a major complication or comorbidity or any complication or comorbidity was evaluated in service claims prior to admission for the index procedure.

Table 2 Complications and post-procedure validity periods

\begin{tabular}{lll}
\hline Priority & Complication category & $\begin{array}{l}\text { Post-procedure } \\
\text { validity period }\end{array}$ \\
\hline I & Infected mesh (removal) & 18 months \\
2 & Infection & 30 days \\
3 & Graft/mesh/wound complication & 18 months \\
& (without mesh removal) & 18 months \\
5 & Hernia recurrence & 90 days \\
6 & Seroma & 18 months \\
& Bowel obstruction/other & \\
7 & gastrointestinal complication & 60 days \\
& Other complication, including: & 60 days \\
& Enteritis/colitis & 14 days \\
& Fistula & 60 days \\
& Hematoma & 30 days \\
& Peritonitis & 6 months \\
& Procedural complication & 18 months \\
& Skin/connective tissue & \\
& Excision of abdominal wall lesion or &
\end{tabular}

Morbid obesity and diabetes were identified by the presence of a defining code (see online appendix) at any point during the two-year data set.

Costs are presented from the hospital perspective. For inpatient admissions, hospital cost was estimated for each relevant Medicare Severity Diagnosis Related Group (MS-DRG) from the 2008 National Inpatient Sample, ${ }^{4}$ using charges and hospital-specific cost-to-charge ratios, where available, and statewide average cost-to-charge ratios otherwise. Average cost per discharge was calculated in the National Inpatient Sample for adult patients and matched to the study events by MS-DRG and the presence or absence of complication diagnosis codes specific to this hernia study. ${ }^{4}$ To avoid understating the hospital cost of extended stays, hospital cost was also computed on a cost-per-day basis using length of stay, and the greater of DRG-derived or length of stay-derived cost was applied to each discharge. For inpatient episodes including subacute care, cost was calculated according to the number of days at each level of care. For outpatient episodes, CPT codes were used to identify a primary Ambulatory Payment Classification code, for which national average hospital cost was applied, as derived from Medicare outpatient visits in 2009 by Cleverley and Associates (Worthington, $\mathrm{OH}, \mathrm{USA}$ ). The estimated cost of xenograft or synthetic mesh was added differentially to the index episodes in the relevant study arms. The cost applied for xenograft was $\$ 8330$ per patient, based on the weighted average sales price of $10 \times 16 \mathrm{~cm}, 16 \times 20 \mathrm{~cm}$, and $20 \times 25 \mathrm{~cm}$ pieces of xenograft as of January 2012 (LifeCell Corporation, Branchburg, NJ, USA). For synthetic mesh, a cost of $\$ 616$ per patient weighted average unit price of synthetic mesh products was used per IMS Health Incorporated (Danbury, CT, USA) data as of October 2011. The average cost was calculated per patient to show the cost contribution of each type of return event to the average total cost per patient over 18 months. All costs are presented in 2012 dollars, inflated at $3 \%$ per annum.

\section{Statistical analysis}

The results are presented as percentages, means (standard deviation), and event rates per 100 patients. Comparisons of population characteristics across study arms were carried out using either analysis of variance or Chi-square tests as appropriate. Comparisons of the downstream occurrence percentages of each complication among the study arms were carried out using Chi-square tests. Comparisons of event rates per 100 patients for each complication among 
the study arms were carried out using Poisson regression likelihood ratio tests.

Due to the inherently skewed nature of cost data and unequal cost variances across study arms, comparisons of cost contributions between study arms were carried out using a nonparametric bootstrap randomization analysis ( $n=5000$ samples) for each type of complication. In addition, 95\% Wald confidence limits for the study arm event rates per 100 patients are provided for each complication. Analysis of variance was used to make comparisons of length of stay across study arms. All post hoc pairwise comparisons of study arms used the Bonferroni stepdown adjustment procedure of Holm, ${ }^{5}$ controlling the familywise error rate at 0.05 . A $P$ value $<0.05$ was considered to be statistically significant. All statistical analyses were carried out using SAS/STAT software version 9.2 of the SAS System for Windows (SAS Corporation, Cary, NC, USA).

\section{Results}

\section{Study population}

A total of 744 patients received ventral hernia repairs during the first six months of 2008, comprising 538 patients with grade 3 hernias and 206 with grade 4 hernias in accordance with the VHWG grading scale (see Table 1). Among the grade 3 patients, 268 received repair reinforced with synthetic mesh, 214 received primary repair, and 56 received repair reinforced with xenograft. Of the grade 4 patients, 121 underwent repair reinforced with xenograft and 85 underwent primary repair. Four patients in the grade 4 group were assumed to have had synthetic mesh used during hernia repair because mesh not subsequently implanted was removed more than 90 days following the index repair. These patients were excluded from comparative analyses due to small sample size. No differences were found in population characteristics, including age, gender, and percentage of patients who were morbidly obese or had diabetes. Among grade 3 patients, significantly fewer of those with xenograft had pre-existing complications $(60.7 \%)$ compared with synthetic mesh patients $(75 \%)$ and primary repair patients $(79.9 \%, P<0.05)$. Table 3 shows the population characteristics of patients with grade 3 and 4 hernias. There was no statistically significant difference in average length of stay for index episodes by type of repair for grade 3 and 4 patients (Table 4). Grade 4 patients stayed in hospital 4.8 days longer, on average. Laparoscopic repair was used in $8 \%$ of index events (10\% in grade 3 patients; $1 \%$ in grade 4 patients). CPT 15734 (muscle-skin graft, trunk) was identified in $5 \%$ of index events (4\% in grade $3 ; 8 \%$ in grade 4 ).

\section{Complication rates in study arms}

Grade 3 xenograft patients had the lowest overall complication rate $(17.9 \%)$ over 18 months compared with synthetic mesh $(36.9 \%)$ and primary repair $(24.3 \%$,

Table 3 Characteristics of study populations with grade 3 and 4 hernias

\begin{tabular}{|c|c|c|c|c|c|}
\hline $\begin{array}{l}\text { Grade } 3 \\
\text { Hernia }\end{array}$ & $\begin{array}{l}\text { Overall sample } \\
(n=538)\end{array}$ & $\begin{array}{l}\text { Xenograft } \\
(n=56)\end{array}$ & $\begin{array}{l}\text { Synthetic mesh } \\
(n=268)\end{array}$ & $\begin{array}{l}\text { Primary repair } \\
(n=2 \mid 4)\end{array}$ & $\begin{array}{l}\text { Overall } \\
P \text { value }\end{array}$ \\
\hline Age, mean (SD), y & $56.4(13.2)$ & $55.4(12.6)$ & $57.0(12.4)$ & $56.0(14.4)$ & $0.5836^{*}$ \\
\hline \multicolumn{6}{|l|}{ Sex, \% } \\
\hline Female $(n=36 \mathrm{I})$ & 67.1 & 55.4 & 67.9 & 69.2 & $0.1368^{\dagger}$ \\
\hline Male $(n=177)$ & 32.9 & 44.6 & 32.1 & 30.8 & \\
\hline Morbid obesity, \% & 8.9 & 5.4 & 10.5 & 7.9 & $0.3876^{\dagger}$ \\
\hline Diabetes, \% & 39.6 & 37.5 & 40.7 & 38.8 & $0.8645^{\dagger}$ \\
\hline MCC, \% & 49.1 & 37.5 & 52.2 & 48.1 & $0.1291^{\dagger}$ \\
\hline CC or MCC, $\%$ & 75.5 & $60.7^{\mathrm{b}}$ & $75.0^{\mathrm{a}}$ & $79.9^{a}$ & $0.0136^{t, f}$ \\
\hline Grade 4 & Overall Sample & Xenograft & & Primary repair & Overall \\
\hline Hernia & $(n=202)$ & $(n=|2|)$ & & $(n=8 I)$ & $P$ value \\
\hline Age, mean (SD), y & $56.5(12.3)$ & $55.1(12.1)$ & & $58.4(12.4)$ & $0.0656^{*}$ \\
\hline \multicolumn{6}{|l|}{ Sex, \% } \\
\hline Female $(n=|3|)$ & 64.9 & 59.5 & & 72.8 & $0.0517^{\dagger}$ \\
\hline Male $(n=7 I)$ & 35.2 & 40.5 & & 27.2 & \\
\hline Morbid obesity, \% & 5.9 & 5.0 & & 7.4 & $0.4733^{\dagger}$ \\
\hline Diabetes, \% & 43.6 & 43.8 & & 43.2 & $0.9337^{\dagger}$ \\
\hline MCC, \% & 44.1 & 39.7 & & 50.6 & $0.1254^{\dagger}$ \\
\hline CC or MCC, $\%$ & 72.8 & 71.9 & & 74.1 & $0.7339^{\dagger}$ \\
\hline
\end{tabular}

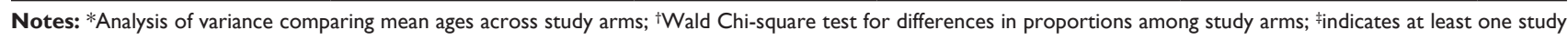
arm has a significantly different rate of occurrence; a,bost-hoc pairwise comparisons were carried out using the Bonferroni stepdown adjustment procedure of Holm controlling the familywise error rate at 0.05 . Study arms connected with the same letter are not significantly different $(P>0.05)$.

Abbreviations: SD, standard deviation; CC, complication or comorbidity; MCC, major complication or comorbidity. 
Table 4 ALOS in index episodes

\begin{tabular}{|c|c|c|c|c|c|}
\hline $\begin{array}{l}\text { Grade } 3 \\
\text { Hernia }\end{array}$ & $\begin{array}{l}\text { Overall sample } \\
(n=529)\end{array}$ & $\begin{array}{l}\text { Xenograft } \\
(n=53)\end{array}$ & $\begin{array}{l}\text { Synthetic mesh } \\
(n=267)\end{array}$ & $\begin{array}{l}\text { Primary repair } \\
(n=209)\end{array}$ & $\begin{array}{l}\text { Overall } \\
P \text { value }\end{array}$ \\
\hline ALOS, mean (SD) & $6.0(9.9)$ & $5.5(5.8)$ & $5.3(6.0)$ & $7.0(13.9)$ & 0.1918 \\
\hline $\begin{array}{l}\text { Grade } 4 \\
\text { Hernia }\end{array}$ & $\begin{array}{l}\text { Overall sample } \\
(n=182)\end{array}$ & $\begin{array}{l}\text { Xenograft } \\
(n=109)\end{array}$ & & $\begin{array}{l}\text { Primary repair } \\
(n=73)\end{array}$ & $\begin{array}{l}\text { Overall } \\
P \text { value }\end{array}$ \\
\hline ALOS, mean (SD) & $10.8(13.1)$ & II.I (I5.0) & & $10.3(9.7)$ & 0.6838 \\
\hline
\end{tabular}

Abbreviations: ALOS, average length of stay; SD, standard deviation.

$P<0.05)$; the difference between xenograft and primary repair was nonsignificant. In each defined category of complication for which differences were significant, synthetic mesh patients experienced the highest complication rate, including mesh removals, infection and graft/mesh/ wound complications, and "other" complications (Table 5). Among grade 4 patients, the difference in overall complication rates between xenograft and primary repair was not significant (Table 6).

\section{Post-index returns for grade 3 patients}

Overall, grade 3 xenograft patients had the lowest return rate (71.4 returns per 100 patients) compared with primary repair (114.0 returns per 100 patients) and synthetic mesh (195.1 returns per 100 patients, $P<0.05$ ). Patients repaired with synthetic mesh returned most often for removal of infected mesh or graft, other infection, graft or mesh complications, and "other" complications, while patients receiving primary repair returned more often for treatment of seroma and bowel obstructions or other gastrointestinalrelated complications. Patients repaired with xenograft had lower return rates in every category except recurrent hernia, where the differences between the study arms did not achieve statistical significance (16.1 versus 15.4 versus 15.3 returns $/ 100$ for xenograft, primary repair, and synthetic mesh, respectively, Table 7).

\section{Post-index returns for grade 4 patients}

Return rates for grade 4 patients showed less variability between the study arms. Patients repaired with xenograft were significantly less likely to return for bowel obstruction or other gastrointestinal complications compared with primary repair patients ( 9.1 returns/ 100 patients versus 43.2 returns/100 patients, respectively, $P<0.0001$ ), but were more likely to return for treatment of "other" complications (19.0 returns/100 xenograft patients versus 7.4 returns/100 primary repair patients, $P=0.0398$ ). Xenograft patients had 5.8 returns per 100 patients for infected graft material. Differences in return rates for the other defined categories of complications did not achieve statistical significance, nor did the difference in overall return rates (85.1 returns/100 patients versus 97.5 returns/100 patients for xenograft and primary repair patients, respectively) (Table 8 ). In the "other complication" category, the vast majority of return visits following repair of both grade 3 and 4 hernias involved skin and tissue complications; most common was a nonhealing surgical wound (ICD-9-CM diagnosis 998.83).

\section{Treatment costs}

Xenograft patients had the most costly initial repair procedure in the grade 3 group $(\$ 28,919)$, but this was not significantly different from primary repair $(\$ 23,473)$. Both xenograft and primary repair were significantly more costly than synthetic

Table 5 Downstream patient complication rates among study arms for each complication - grade 3

\begin{tabular}{|c|c|c|c|c|}
\hline n (\%) & $\begin{array}{l}\text { Xenograft } \\
(n=56)\end{array}$ & $\begin{array}{l}\text { Synthetic mesh } \\
(n=268)\end{array}$ & $\begin{array}{l}\text { Primary repair } \\
(n=214)\end{array}$ & $P$ value \\
\hline Infected mesh removal & $2(3.6)^{\mathrm{a}}$ & $6 \mathrm{I}(22.8)^{\mathrm{b}}$ & $2(0.9)^{\mathrm{a}}$ & $<0.000 I^{*}$ \\
\hline Infection & $4(7.1)^{\mathrm{a}}$ & $70(26.1)^{b}$ & $21(9.8)^{\mathrm{a}}$ & $<0.000 I^{*}$ \\
\hline Graft/mesh/wound complication & $4(7.1)^{\mathrm{a}}$ & $62(23.1)^{\mathrm{b}}$ & $17(7.9)^{\mathrm{a}}$ & $<0.000 I^{*}$ \\
\hline Hernia recurrence & $9(16.1)$ & $62(23.1)$ & $39(18.2)$ & 0.2889 \\
\hline Seroma & $\mathrm{I}(\mathrm{I} .8)$ & $15(5.6)$ & $7(3.3)$ & 0.3039 \\
\hline Bowel obstruction/other gastrointestinal complication & $2(3.6)$ & $45(16.8)$ & $30(14.0)$ & 0.0628 \\
\hline Other complication & $4(7.1)^{\mathrm{a}}$ & $52(19.4)^{b}$ & $21(9.8)^{\mathrm{a}}$ & $0.0040 *$ \\
\hline Overall rate of complication & $10(17.9)^{\mathrm{a}}$ & $99(36.9)^{\mathrm{b}}$ & $52(24.3)^{\mathrm{a}}$ & $0.0014^{*}$ \\
\hline
\end{tabular}

Notes: Wald Chi-square test for differences in proportions among study arms. a,bost-hoc pairwise comparisons were carried out using the Bonferroni stepdown adjustment procedure of Holm controlling the familywise error rate at 0.05 . Study arms connected with the same letter are not significantly different $(P>0.05)$; $*$ indicates significant difference in the complication rate for at least one study arm. 
Table 6 Downstream patient complication rates among study arms for each complication - grade $4 *$

\begin{tabular}{llll}
\hline $\mathbf{n}(\%)$ & $\begin{array}{l}\text { Xenograft } \\
(\mathbf{n}=\mathbf{1} \mathbf{2} \mathbf{)})\end{array}$ & $\begin{array}{l}\text { Primary } \\
\text { Repair } \\
(\mathbf{n}=\mathbf{8} \text { I) }\end{array}$ & P value \\
\hline Infected mesh removal & $7(5.8)$ & $0(0)$ & $*$ \\
Infection & $12(9.9)$ & $9(11.1)$ & 0.7854 \\
Graft/mesh/wound complication & $13(10.7)$ & $6(7.4)$ & 0.4287 \\
Hernia recurrence & $16(13.2)$ & $14(17.3)$ & 0.4275 \\
Seroma & $6(5.0)$ & $0(0)$ & $*$ \\
Bowel obstruction/other & $13(10.7)$ & $13(16.0)$ & 0.2724 \\
gastrointestinal complication & & & \\
Other complication & $16(13.2)$ & $7(8.6)$ & 0.3184 \\
Overall rate of complication & $26(21.5)$ & $19(23.5)$ & 0.7417 \\
\hline
\end{tabular}

Notes: Wald Chi-square test for differences in proportions among study arms. *Study arm with no episodes was removed from analysis; no statistical comparisons were done.

mesh $(\$ 18,595, P<0.05)$. When 18-month costs were taken into account, total costs for xenograft patients were $\$ 33,266$ versus $\$ 34,948$ for primary repair and $\$ 35,891$ for synthetic mesh (difference not statistically significant). For xenograft patients, treatment of complications represented $13 \%$ of total costs (\$4347), which was lower but not significantly different from the $33 \%$ of total costs for primary repair patients $(\$ 11,474)$; however, both were significantly lower than the $48 \%$ of total costs for synthetic mesh patients $(\$ 17,296$, $P<0.05)$.

Tables 9 and 10 contain average per-patient costs for the index procedure and each category of downstream complication for grade 3 and 4 patients, respectively. Initial repair costs were much higher for grade 4 patients compared with grade 3 patients, averaging \$12,278 more for xenograft patients and $\$ 13,601$ more for primary repair patients, largely due to the extended length of stay. For grade
4, costs for xenograft and primary repair patients were similar (\$50,154 versus $\$ 46,091$, difference not statistically significant).

Treatment of complications represented $16.7 \%$ $(\$ 8383 / \$ 50,154)$ of total costs for grade 4 xenograft patients versus $19.6 \%(\$ 9016 / \$ 46,091)$ of total costs for primary repair patients. Individual comparisons of defined categories of complications failed to show significant differences in average costs per patient with ventral hernia.

\section{Discussion}

To our knowledge, this is the first study to access a large medical insurance claims database to report on costs and health resource utilization associated with repair of complex ventral hernias and comparing methods of surgical repair. Our study focused on patients with particularly challenging hernias, classified as grade 3 and 4 based on recommendations from the VHWG, due to the presence of infection or potential contamination.

We found no significant differences in overall 18-month hospital costs between synthetic mesh, xenograft, or primary repair in grade 3 and 4 patients, but the distribution of costs varied significantly by study arm. Index hospitalizations were more expensive in the xenograft arm, largely due to the cost of xenograft. However, for grade 3 patients, xenograft repairs had the lowest incidence of downstream complications, the lowest return rate among the three study arms, and the lowest cost of complications. Synthetic mesh patients fared least well in grade 3 hernia repairs; the incidence of complications was nearly twice as high in this arm compared with the xenograft arm $(36.9 \%$ versus $17.9 \%, P<0.05)$, return rates were nearly three times higher (195.1 events/100

Table 7 18-month event rate comparisons - grade 3

\begin{tabular}{|c|c|c|c|c|}
\hline $\begin{array}{l}\text { Non-index events per } \\
100 \text { patients }(95 \% \mathrm{Cl})\end{array}$ & $\begin{array}{l}\text { Xenograft } \\
(n=56)\end{array}$ & $\begin{array}{l}\text { Synthetic mesh } \\
(\mathrm{n}=268)\end{array}$ & $\begin{array}{l}\text { Primary repair } \\
(n=2 \mid 4)\end{array}$ & $\begin{array}{l}\text { Overall } \\
P \text { value }\end{array}$ \\
\hline Infected mesh removal & $5.4^{\mathrm{a}}(1.7,16.6)$ & $29.5^{b}(23.6,36.8)$ & $0.9^{a}(0.2,3.7)$ & $<0.000 I^{*}$ \\
\hline Infection & $8.9^{\mathrm{b}}(3.7,21.5)$ & $41.0^{\mathrm{a}}(34.0,49.5)$ & $30.8^{\mathrm{a}}(24.2,39.3)$ & $<0.000 I^{*}$ \\
\hline Graft/mesh/wound complication & $12.5^{\mathrm{a}, \mathrm{b}}(6.0,26.2)$ & $26.5^{\mathrm{a}}(21.0,33.4)$ & $6.1^{b}(3.5,10.5)$ & $<0.000$ I* $^{*}$ \\
\hline Hernia recurrence & I6.I $(8.4,30.9)$ & I5.3 (II.3, 20.8) & $15.4(\mid 1.0,21.7)$ & 0.9912 \\
\hline Seroma & $1.8(0.3,12.7)$ & $6.7(4.2,10.7)$ & II.2(7.5, 16.7) & $0.0302^{\dagger}$ \\
\hline $\begin{array}{l}\text { Bowel obstruction/other gastrointestinal } \\
\text { complication }\end{array}$ & $0.0(0)$ & $13.4(9.7,18.6)$ & $15.4(11.0,21.7)$ & 0.5674 \\
\hline Other complication & $26.8^{\mathrm{a}}(16.1,44.4)$ & $62.7^{\mathrm{b}}(53.9,72.9)$ & $34 . I^{\mathrm{a}}(27.1,42.9)$ & $<0.000 I^{*}$ \\
\hline Total & $71.4^{\mathrm{a}}(52.4,97.4)$ & $195 . I^{\mathrm{b}}(179.1,212.6)$ & II4.0c $(100.6,129.3)$ & $<0.000 I^{*}$ \\
\hline
\end{tabular}

Notes: *Poisson regression likelihood ratio test indicates at least one study arm has a significantly different non-index event rate; the overall Poisson regression likelihood ratio test indicates at least one study arm has a significantly different non-index event rate; however, post-hoc comparisons found no significant pairwise differences; ${ }_{a, b, c}$ post-hoc pairwise comparisons were carried out using the Bonferroni stepdown adjustment procedure of Holm controlling the familywise error rate at 0.05 . Study arms connected with the same letter are not significantly different $(P>0.05)$.

Abbreviation: $\mathrm{Cl}$, confidence interval. 
Table 8 18-month event rate comparisons - grade 4

\begin{tabular}{|c|c|c|c|}
\hline $\begin{array}{l}\text { Non-index events } \\
\text { per } 100 \text { patients } \\
(95 \% \mathrm{Cl}) \\
\end{array}$ & $\begin{array}{l}\text { Xenograft } \\
(n=|2|)\end{array}$ & $\begin{array}{l}\text { Primary } \\
\text { repair } \\
(\mathbf{n}=\mathbf{8} 1)\end{array}$ & $\begin{array}{l}\text { Overall } \\
P \text { value }\end{array}$ \\
\hline $\begin{array}{l}\text { Infected mesh } \\
\text { removal }\end{array}$ & $5.8(2.3,11.9)$ & $0.0(0)$ & $*$ \\
\hline Infection & $21.5(14.6,31.6)$ & $22.2(14.0,35.3)$ & 0.9128 \\
\hline $\begin{array}{l}\text { Graft/mesh/wound } \\
\text { complication }\end{array}$ & $11.6(6.9,19.5)$ & $12.3(6.6,22.9)$ & 0.8757 \\
\hline Hernia recurrence & $10.7(6.2,18.5)$ & $12.3(6.6,22.9)$ & 0.7419 \\
\hline Seroma & $7.4(3.4,14.1)$ & $0.0(0)$ & $*$ \\
\hline $\begin{array}{l}\text { Bowel obstruction/ } \\
\text { other gastrointestinal } \\
\text { complication }\end{array}$ & $9.1(5.0,16.4)$ & $43.2(31.0,60.2)$ & $<0.000 \mathrm{I}^{\dagger}$ \\
\hline Other complication & $19.0(12.6,28.6)$ & $7.4(3.3,16.5)$ & $0.0398^{\dagger}$ \\
\hline Total & $85.1(70.2,103.3)$ & $97.5(78.2,121.6)$ & 0.3646 \\
\hline
\end{tabular}

Notes: *Study arm with no episodes was removed from analysis; no statistical comparisons were done; 'Poisson regression likelihood ratio test indicates a significantly different non-index event rate.

Abbreviation: $\mathrm{Cl}$, confidence interval.

patients versus 71.4 events $/ 100$ patients, $P<0.05$ ), and treatment costs of complications were roughly four times higher ( $\$ 17,296$ versus $\$ 4397, P<0.05)$.

The size of these differences was much smaller in the grade 4 hernia population, likely reflecting the severity of

Table 9 Average cost per hernia patient, index event and following complications- grade 3

\begin{tabular}{|c|c|c|c|c|}
\hline$\$$, Mean (SD) & $\begin{array}{l}\text { Xenograft } \\
(n=53)\end{array}$ & $\begin{array}{l}\text { Synthetic } \\
\text { mesh } \\
(n=267)\end{array}$ & $\begin{array}{l}\text { Primary } \\
\text { repair } \\
(n=209)\end{array}$ & $\begin{array}{l}\text { Overall } \\
P \text { value }\end{array}$ \\
\hline Index episode & $\begin{array}{l}28,919^{b} \\
(13,094)\end{array}$ & $\begin{array}{l}18,595^{a} \\
(13,970)\end{array}$ & $\begin{array}{l}23,473^{\mathrm{b}} \\
(25,377)\end{array}$ & $0.0014^{*}$ \\
\hline $\begin{array}{l}\text { Infected mesh } \\
\text { (removal) }\end{array}$ & $\begin{array}{l}744^{\mathrm{a}} \\
(4,776)\end{array}$ & $\begin{array}{l}7,528^{\mathrm{b}} \\
(27,453)\end{array}$ & $\begin{array}{l}403^{\mathrm{a}} \\
(4,846)\end{array}$ & $0.0012^{*}$ \\
\hline Infection & $\begin{array}{l}988 \\
(3,827)\end{array}$ & $\begin{array}{l}3,87 \mid \\
(14,689)\end{array}$ & $\begin{array}{l}4,737 \\
(17,520)\end{array}$ & 0.2830 \\
\hline $\begin{array}{l}\text { Graft/mesh/wound } \\
\text { complication }\end{array}$ & $\begin{array}{l}489 \\
(2,743)\end{array}$ & $\begin{array}{l}1,168 \\
(5,269)\end{array}$ & $\begin{array}{l}829 \\
(7,654)\end{array}$ & 0.7464 \\
\hline Hernia recurrence & $\begin{array}{l}I, 454 \\
(4,448)\end{array}$ & $\begin{array}{l}2,049 \\
(6,175)\end{array}$ & $\begin{array}{l}2,645 \\
(9,265)\end{array}$ & 0.5032 \\
\hline Seroma & $\begin{array}{l}30 \\
(219)\end{array}$ & $\begin{array}{l}248 \\
(1,659)\end{array}$ & $\begin{array}{l}260 \\
(2,621)\end{array}$ & 0.8114 \\
\hline $\begin{array}{l}\text { Bowel obstruction/ } \\
\text { other gastrointestinal } \\
\text { complication }\end{array}$ & $0(0)$ & $\begin{array}{l}1,395 \\
(7,213)\end{array}$ & $\begin{array}{l}I, 795 \\
(I 6, I 4 I)\end{array}$ & 0.7522 \\
\hline Other complication & $\begin{array}{l}642 \\
(2,923)\end{array}$ & $\begin{array}{l}1,038 \\
(4,677)\end{array}$ & $\begin{array}{l}806 \\
(5,576)\end{array}$ & 0.8326 \\
\hline $\begin{array}{l}\text { Subtotal: downstream } \\
\text { complications }\end{array}$ & $\begin{array}{l}4,347^{a} \\
(13,700)\end{array}$ & $\begin{array}{l}17,296^{b} \\
(36,961)\end{array}$ & $\begin{array}{l}I I, 474^{a, b} \\
(33,572)\end{array}$ & $0.0248 *$ \\
\hline Total & $\begin{array}{l}33,266 \\
(18,784)\end{array}$ & $\begin{array}{l}35,891 \\
(39,701)\end{array}$ & $\begin{array}{l}34,948 \\
(42,774)\end{array}$ & 0.4040 \\
\hline
\end{tabular}

Notes: *Nonparametric bootstrap (5,000 replications) indicates at least one study arm has a significantly different mean cost for that episode; a,bost-hoc pairwise comparisons of bootstrap means were carried out using the Bonferroni stepdown adjustment procedure of Holm controlling the familywise error rate at 0.05 . Study arms connected with the same letter are not significantly different $(P>0.05)$.

Abbreviation: SD, standard deviation.
Table 10 Average cost per hernia patient for complication treatments for each study arm - grade 4

\begin{tabular}{|c|c|c|c|}
\hline$\$$, Mean (SD) & $\begin{array}{l}\text { Xenograft } \\
(n=109)\end{array}$ & $\begin{array}{l}\text { Primary } \\
\text { repair } \\
(n=73)\end{array}$ & $\begin{array}{l}\text { Overall } \\
P \text { value }\end{array}$ \\
\hline Index episode & $4 I, 197(32,23 I)$ & $37,074(26,530)$ & 0.3678 \\
\hline $\begin{array}{l}\text { Infected mesh } \\
\text { (removal) }\end{array}$ & $2,807(17,016)$ & $0(0)$ & $*$ \\
\hline Infection & $1,839(7,6 \mid 4)$ & $2,896(9,710)$ & 0.4206 \\
\hline $\begin{array}{l}\text { Graft/mesh/wound } \\
\text { complication }\end{array}$ & $407(3,185)$ & $217(1,504)$ & 0.7994 \\
\hline Hernia recurrence & $\mathrm{I}, 238(4,06 \mathrm{I})$ & $2,639(9,119)$ & 0.1656 \\
\hline Seroma & $220(1,236)$ & $0(0)$ & $*$ \\
\hline $\begin{array}{l}\text { Bowel obstruction/ } \\
\text { other gastrointestinal } \\
\text { complication }\end{array}$ & $\mathrm{I}, 897(12,776)$ & $3,15 I(16,240)$ & 0.5544 \\
\hline Other complication & $550(3,059)$ & $113(680)$ & 0.2586 \\
\hline $\begin{array}{l}\text { Subtotal: downstream } \\
\text { complications }\end{array}$ & $8,958(33,375)$ & $9,016(24,706)$ & 0.8962 \\
\hline Total & $50,154(45,506)$ & $46,091(36,197)$ & 0.5318 \\
\hline
\end{tabular}

Notes: Nonparametric bootstrap (5,000 replications) comparisons of mean costs between study arms. *Study arm with no episodes was removed from analysis; no statistical comparisons were done.

Abbreviation: SD, standard deviation.

infections characterizing this group of patients at initial repair. Initial repairs were much costlier for grade 4 patients compared with the grade 3 group, in large part due to a greater length of stay; grade 4 patients stayed in hospital nearly twice as long as grade 3 patients and cost a minimum of about $\$ 10,000$ more for the initial repair.

The results of our study suggest that downstream complications result in frequent returns for additional services and are a significant contributor to the economic cost of ventral hernia repair during the first few years subsequent to surgical repair. In grade 4 patients, the overall costs were similar between xenograft and primary repair. Among grade 3 patients, the higher costs and complication rates observed with synthetic mesh support use of biologic mesh or primary repair for these cases. This supports the recommendations of the subsequently published VHWG recommendation against the use of permanent synthetic material in open repairs of grade 3 incisional ventral hernias. Based on these findings, hospitals, health plans, and surgeons should carefully weigh the higher initial cost of biologic matrices against the reduced complications and costs post-procedure. These results also provide a basis for future comparisons of cost-effectiveness in ventral hernia repair, particularly in the setting of infection or contamination.

Studies using insurance claims databases have inherent limitations because analysis is limited to services reported by diagnosis and procedure codes, which lack the precision 
of medical chart data. In particular, insurance data fields offer no means to compare hernia size, nor do they clearly distinguish the reasons for surgical mesh removal; further, they do not support detailed analyses of the use of inhospital services that may affect hospital costs. Additionally, some complications may not be reported accurately using ICD-9 codes. We noted, for example, the absence of seromas in grade 4 primary repairs even though seromas are known to be a common event and were found in 3.3\% of patients undergoing primary repair of a grade 3 hernia. Further, our inability to classify removed mesh as infected in a definitive way could have affected our classification of hernias as grade 4 versus grade 3. Also, the retrospective nature of this analysis makes it difficult to control directly for other factors that may influence outcomes. Nevertheless, insurance claims offer a means for preliminary assessment of alternative surgical approaches in large patient populations, enabling comparison of alternative surgical approaches performed contemporaneously in multiple centers and geographic regions.

\section{Conclusion}

In this study of patients with complex ventral hernia, clinical outcomes and costs associated with synthetic mesh repairs compared unfavorably with both xenograft and primary repair in nearly every category of comparison. Xenograft and primary repair patients had similar outcomes in most categories, although xenograft patients had lower return rates for treatment of complications overall and infection, particularly in grade 3 patients. Further prospective, controlled comparative studies of outcomes and costs are warranted.

\section{Disclosure}

GD is a speaker for LifeCell Corporation and Olympus Corporation. NR and SF are independent contractors for Strategic Health Resources, a consulting company, and work with a number of device and drug manufacturers. In this case, LifeCell Corporation provided financial support for the research referenced in this manuscript. Editorial support for this article was provided by Peloton Advantage, LLC, Parsippany, NJ, and funded by LifeCell Corporation. The authors report no other conflicts of interest in this work.

\section{References}

1. Poulose BK, Shelton J, Phillips S, et al. Epidemiology and cost of ventral hernia repair: making the case for hernia research. Hernia. 2012;16(2): $179-183$.

2. den Hartog D, Dur AH, Tuinebreijer WE, Kreis RW. Open surgical procedures for incisional hernias. Cochrane Database Syst Rev. 2008;3: CD006438.

3. Breuing K, Butler CE, Ferzoco S, et al. Incisional ventral hernias: review of the literature and recommendations regarding the grading and technique of repair. Surgery. 2010;148(3):544-558.

4. Cost-to-charge ratio files. Agency for Healthcare Research and Quality. Available from: http://www.hcup-us.ahrq.gov/db/state/costtocharge.jsp. Accessed January 21, 2013.

5. Holm S. A simple sequentially rejective Bonferroni test procedure. Scand J Statistics. 1979;6:65-70. 


\section{Supplementary online appendix \\ Patient inclusions: grade 3 or 4 hernia}

Grade 4 hernia (infected) was assigned for infected mesh or septic dehiscence. If mesh was removed in conjunction with the hernia repair, it was assumed to be infected. Infected mesh was identified as one of the following: CPT code 11008 (remove mesh from abdominal wall); the presence of a CPT code indicating draining of an abscess or debridement (11005, 11010, 11011, 11040, 11042, 11043, 44900, 49020, 49021, 49040, 49041, 49060, or 49061) concurrent with the index hernia repair or within the preceding two days; or the presence of one of the following CPT codes for hernia repair (49565, 49566, 49568, 49656, 49657, 49659, S2075, or S2077) and a diagnosis code indicating infection (551.20, 551.21, 551.29, 569.5, 569.61, 569.81, 682.2, 682.9, 686.8, $686.9,728.86,785.4,879.3,879.5,879.7,879.9,958.3$, $995.91,996.60,996.69,998.51$, or 998.59) concurrent with the index hernia repair or within the preceding two days.

Due to limitations of the data set, septic dehiscence was defined as the presence of diagnosis code(s) confirming either septicemia (003.1, 036.2, 038, 038.0, 038.1, 038.10, 038.11, 038.12, 038.19, 038.2, 038.3, 038.4, 038.40, 038.41, 038.42, $038.43,038.44,038.49,038.8,038.9,054.5,449,785.52$, or 790.7 ) or dehiscence $(998.3,998.31$, or 998.32) in a claim for a single date of service within two days before or after the index date. (Claims covering a range of dates, such as hospital bills, were excluded because conditions present on admission cannot be distinguished from conditions developing postoperatively during the hospital stay).

Grade 3 (potentially contaminated) was assigned to hernia repairs involving a previous wound infection, violation of the gastrointestinal tract, or creation/revision of a stoma concurrent with the index hernia repair. Diagnosis codes occurring in services during 2008 prior to the index date were used to identify previous wound infection $(551.20,551.21,551.29$, 566, 569.5, 569.61, 879.3, 879.5, 958.3, 995.91, 995.92, $996.6,996.60,996.68,996.69,998.5,998.51$, or 998.59 ; or any code for septicemia or dehiscence, as defined for grade 4 above). Stoma creation was defined by CPT code 43886 , 44151, 44152, 44153, 44155, 44186, 44187, 44188, 44201, 44203, 44206, 44210, 44211, 44212, 44227, 44300, 44310, 44312, 44314, 44316, 44320, 44322, 44340, 44345, 44346, $44500,44605,44700,45136,45355$, or 57307 . Violation of the gastrointestinal tract was identified by CPT code 38780 , 38792, 43330, 43499, 44151, 44152, 44153, 44155, 44186, 44188, 44201, 44206, 44210, 44211, 44212, 44227, 44310, 44312, 44314, 44316, 44320, 44322, 44340, 44345, 44346, 44605, 45136, or 57307.

\section{Patient exclusions: post-transplant status or concurrent bariatric surgery}

Patients were excluded if diagnosis codes present during or before the index hospitalization showed a history of major organ transplantation $(996.8,996.80,996.81,996.82,996.83$, 996.84, 996.86, 996.87, 996.89, V42.0, V42.1, V42.2, V42.4, V42.6, V42.7, V42.83, or V42.84), or if CPT codes during the index hospitalization indicated concurrent bariatric surgery $(43644,43645,43770,43771,43772,43773,43774$, 43842, 43843, 43845, 43846, 43847, 43848, 43850, 43855, or 43860).

\section{Descriptive characteristics Morbid obesity}

Consistent with coding usage in 2008, morbid obesity was identified by diagnosis codes 278.01 (obesity, morbid) or V85.4 (body mass index $\geq 40$, adult).

\section{Diabetes}

Diabetes was defined as presence of a diagnosis code beginning 249 or 250, or any of the following codes: 253.5, 790.2, $790.21,790.22,790.29,791.5,791.6, \mathrm{~V} 45.85$, V53.91, or V65.46.

\section{Complications} Infected mesh

Any downstream episode with CPT 11008 OR, in the synthetic mesh study arm, any downstream episode with ICD9 diagnosis codes 996.60 or 996.69 or a combination of diagnosis and procedure codes*; in the xenograft study arm, any downstream episode with ICD9 diagnosis codes 996.60 or 996.69 or a combination of diagnosis and procedure codes* if the episode occurred within 90 days following the index event (otherwise, the classification changes to infection); in the primary repair study arm, any downstream episode with ICD9 diagnosis codes 996.60 or 996.69 or a combination of diagnosis and procedure codes* occurring subsequent to a post-index implantation of mesh (otherwise, the classification changes to infection).

*The qualifying combination of diagnosis and procedures is an episode that includes a hernia procedure code (CPT code 49560, 49561, 49565, 49566, 49652, 49653, 49654, 49655, 49656, 49657, 49659, S2075, S2077, 11005, 11010, 11011, 11040, 11042, 11043, 44900, 49020, 49021, 49040, 49041, 49060 , or 49061; or ICD-9 procedure code 46.42, 53.51, $53.59,53.61,53.69,53.9,54.0,54.12,54.3,54.59,54.72$, $83.44,86.04,86.22$, or 86.28) AND confirmation of infection from a diagnosis code $(958.3,995.91,998.51,996.69$, 
551.20, 569.61, 879.3, 785.4, 728.86, 686.9, 686.8, 682.9, 996.60, 569.81, 879.5, 569.5, 551.29, 551.21, 998.59, 879.7, 879.9 , or 682.2) or CPT code for debridement or draining an abscess (49020, 49061, 49060, 49041, 49021, 44900, 11043, $11042,11040,11011,11010$, or 11005).

\section{Infection}

Diagnosis code 569.61, 682.2, 682.9, 686.9, 728.86, 785.4, 958.3, 995.91, 998.5, 998.51, 998.59, 996.60, 996.69, 038.0, 038.1, 038.10, 038.11, 038.12, 038.19, 038.2, 038.3, 038.4, 038.40, 038.42, 038.43, 038.44, 038.49, 038.8, 038.9, 785.52, or 790.7; CPT code 11005 (debridement); or ICD-9 procedure code $54.0,86.04,86.22$, or 86.28 .

\section{Graft/mesh/wound complication (without mesh removal)}

Events not meeting the criteria for infected mesh specified above that had one or more of the following diagnosis codes: 569.62, 995.3, 996.59, 996.60, 996.69, 996.70, 996.79, $879.2,879.3,879.4,879.5,879.7,879.8,998.3,998.30$, or 998.31.

\section{Recurrence of hernia}

CPT code 49560, 49561, 49565, 49566, 49652, 49653, 49654, 49655, 49656, 49657, 49659, S2075, or S2077; or ICD-9 procedure code 53.51, 53.61, or 53.69.

\section{Seroma}

Diagnosis code 998.13 (seroma complicating a procedure).

\section{Bowel obstruction/other gastrointestinal complication}

Diagnosis code 560.2, 560.81, 560.89, 560.9, 568.0, 569.5, $569.60,569.69,569.83,569.89,577.0,789.5$, or 997.4 ; or ICD-9 procedure code 54.59 .

\section{Other complications}

- Enteritis/colitis, diagnosis code 555.0, 555.1, 555.2, 555.9 , or 556.9 .

- Fistula, diagnosis code 537.4, 569.81, 576.4, 596.1, or 998.6; or CPT 44640.

- Hematoma, diagnosis code 998.12.

- Peritonitis, diagnosis code 567.2, 567.22, 567.29, 567.38, 567.8, 567.89, 567.9, 568.81, 568.82, 568.89, or 568.9.

- Procedural complication, diagnosis code 998.0, 998.1, 998.11, 998.2, or 998.8 .

- Skin/connective tissue, diagnosis code 709.2, 709.4, 728.83, 729.30, 729.4, 909.3, 998.32, 998.83, 998.89, 998.9, 999.9, or E87.88.

- Excision of abdominal wall lesion or reopening of recent laparotomy, ICD-9 procedure code 54.3 or 54.12 .

All diagnosis codes listed above are ICD-9-CM (International Classification of Diseases, Ninth Revision, Clinical Modification).
Open Access Surgery

\section{Publish your work in this journal}

Open Access Surgery is an international, peer-reviewed, open access journal that focuses on all aspects of surgical procedures and interventions. Patient care around the peri-operative period and patient outcomes post surgery are key topics. All grades of surgery from minor cosmetic interventions to major surgical procedures are covered. Novel techniques

\section{Dovepress}

and the utilization of new instruments and materials, including implants and prostheses that optimize outcomes constitute major areas of interest. The manuscript management system is completely online and includes a very quick and fair peer-review system. Visit http://www.dovepress.com/ testimonials.php to read real quotes from published authors. 